\title{
ISO 9001 Aspects Related to Performance and Their Level of Implementation
}

\author{
Jordi Castello Dalmau(iD, Gerusa GimeneziD, Rodolfo De Castroii \\ Universitat de Girona (Spain) \\ u1923606@,campus.udg.edu,gerusa.gimenez@udg.edu, rudi.castro@udg.edu
}

Received: July 2016

Accepted: October 2016

\section{Abstract:}

Purpose: In the last three decades, thousands of companies around the world have embraced the ISO 9001 standard in their quest to improve company performance and customer satisfaction. In recent literature, a number of authors have identified different "levels" of ISO 9001 implementation. This study aims to analyse these implementation levels in companies from the point of view of the customer, and provide guidelines for future improvement.

Design/methodology/approach: Research was conducted based on the results of the secondparty audits (SPAs) of 90 suppliers, (including component suppliers, assemblers, and wind farm operation and maintenance services), to one of the wind power industry's largest wind turbine manufacturers. The audits were carried out within the ISO 9001:2008 framework and conducted by one of this study's authors in his role as the wind turbine company's Director of Global Quality.

Findings: Auditing suppliers plays a unique role in helping to isolate system weaknesses, identify opportunities and suggest areas for improvement. This study shows that, in terms of management commitment and culture and the good practices of an organization, ISO 9001 certified companies implement differing degrees of the standard. From the results of this research, a "road map" towards improvement can be established; one that allows companies in the sector to go beyond simply being accredited with the standard and instead to take advantage of ISO 9001 certification as a catalyst for change. 
Research limitations/implications: This article focuses only on the wind power sector, although its findings could be extrapolated to similar sectors of high technology and high levels of customization.

Originality/value: While quality audits are a customary topic for academics and researchers, few contributions are related to SPAs and their impact on the quality control process of company suppliers. Primary data from the SPAs of suppliers (objective data collected by one of the paper's authors), was used here and is one of the most valuable aspects of this paper's contribution.

Keywords: ISO 9001, supplier audit, second/third party audits, implementation level, factor analysis, wind power sector

\section{Introduction}

In the past three decades, thousands of companies around the world have embraced the ISO 9001 standard in their quest to improve company performance and customer satisfaction. However, despite having been internationally recognized and widely accepted since its publication in 1987, the standard has been subject to controversy and criticism concerning the success or failure of its implementation and/or whether its costs outweigh the performance benefits for companies.

The literature is full of research articles describing ISO 9001 certification successes and failures and the resulting impacts on company profits and performance. For instance, Curkovic and Pagell (1999) point out that ISO 9001 is not connected directly to product quality, and Naveh and Marcus (2005) emphasize that a certified company could still have substandard processes and products because certification does not instruct the company on how to design more reliable and efficient products. Romano (2002) reported that ISO 9001 certification is a letter of access (a visiting card) for many companies and Sroufe and Curkovic (2008) state that, "ISO registration alone is not enough to do anything beyond ensure compliance with the registration standard". Some authors refer to the certification as a "meaningless piece of paper" which is nothing but a cost to a company. Other researchers argue that certification does not ensure an improvement in a firm's performance (Anderson, Daly \& Johnson, 1999; Dimara, Skuras, Tsekouras \& Goutsos, 2004; Morris, 2006; Power \& Terziovski, 2007; Tsekouras, Dimara \& Skuras, 2002) and there are many studies that show companies who have adopted ISO 9001 certification as a result of customer pressure (Anderson et al., 1999; Davis, 2004; Martínez-Costa, Martínez-Lorente \& Choi, 2008).

Nevertheless, it is not all criticism and controversy. There are studies that highlight how ISO 9001 can help companies improve their performance and efficiency. Some point out that certification improves 
product and service quality as well as collaboration with suppliers, and reduces customer complaints and internal costs, thus boosting company profitability (Zaramdini, 2007; Casadesús \& Karapetrovic, 2005), while others stress that certification strengthens workforce motivation, increases market share and facilitates the international expansion of the company (Brown, Wiele \& Loughton, 1998; Zaramdini, 2007). Chow-Chua, Goh and Boon-Wan (2003) also note that ISO certification improves processes and procedures, enhances a company's image in the marketplace, as well as assisting its international expansion.

As a result of the controversy aroused by the ISO 9001 standard and its supposed strengths and weaknesses, we were motivated to analyse to what levels it has been implemented in the wind energy sector by means of second-party audits (SPA).

\subsection{Quality Audits}

For many years the quality audit has played an important role in an organisation's quality management system. Initially used to control financial statements, it has gone on to become a useful management tool in business competitiveness and performance.

ISO 9001 accreditation requires a third-party audit (TPA) certification process to evaluate whether the quality management system complies with the standard's requirements. TPAs are performed by external, independent certification bodies free of any conflict of interest and thus, a key component of a TPA. However, after more than two decades of using TPAs, many quality and manufacturing managers and professionals do not see the value in or the need for them. Some studies reveal significant differences between the perceptions (in terms of profits, performance, standard compliance, improvements, etc.) of auditing that customers have and those that the auditors themselves have (Power \& Terziovski, 2007; Castka, Prajogo, Sohal \& Yeung, 2015). Consequently, there is no better understanding in how academics and practitioners perceive the TPAs process either (Kluse, 2013).

TPAs and their efficiency is a very commonplace theme for many academics and researchers, but very few a have actually focussed their work on SPAs, i.e. when a company performs an audit of a supplier and the impact they have on the whole quality control process (Ferenčíková \& Briš, 2013) as well as in the process improvement (Prasad, Kamath, Barkur \& Nayak, 2016).

The study carried out by Power and Terziovski (2007), highlights a number of differences in perceptions of auditing that customers and auditors have in terms of compliance versus improvement. Karapetrovic and Willborn (2000) point out that the quality audits typically evaluate whether the QMS activities 
conform to the documented procedures are effectively implemented and suitable for achieving the quality targets proposed.

In some industrial sectors, for instance the automotive sector, power systems, oil and gas, wind energy, aerospace and the food industry, purchasing managers push for ISO certification (TPAs) of their suppliers bidding for some projects or tenders. Following this, the customer quality team will later perform SPAs of the same suppliers in order to ensure product quality. However, TPAs, from the managers and practitioners' point of view, only consume resources, time, and money and do not add any value to the company.

\subsection{ISO 9001 Implementation Levels}

In recent literature, several authors have identified different "levels of implementation" of the ISO 9001 standard.

Naveh and Marcus (2004) classified ISO 9001 into two major levels based on practical issues: (i) assimilation, which means establishing rules that allow an organization to effectively adhere to ISO 9001 (quality manual, policies and procedures) and coordinating with external suppliers and customers so that the requirements of the standards fit the needs of the stakeholders, and (ii) go beyond, where the ISO 9001 is used as a springboard for developing additional quality initiatives. In other words, simply being ISO 9001 is not enough, the standard must be used in daily practice and as a catalyst for change (Naveh \& Marcus, 2005).

Sroufe and Curkovic (2008), working with the Miles and Snow (1978) framework, classified the different levels of the ISO implementation into (i) defenders, (ii) reactors, (iii) analysers and (vi) prospectors. Defenders look firstly at improving efficiency in existing operations and are focused on cost. Reactors perceive ISO certification as a cost of doing business, and may struggle with finding any real benefits from ISO certification. Analysers include firms that usually operate in two types of product-market, one which is relatively stable and the other which is changeable. While analysers are successfully operating in more than one product domain, they do not have ISO certification for all those domains. Finally, prospectors' firms are continuously searching for new market opportunities and perceive ISO certification as a new opportunity to achieve competitive advantages.

Prajogo, Huo and Han (2012) identified the following three levels of the ISO 9000 implementation, (i) basic (ii) advanced and (iii) supportive. 
Basic implementation is when the company strictly follows the ISO 9001 requirements. According to Bradley (1994) and Naveh and Marcus (2005), while these practices are an important first step, they are not enough to yield successful improvements. Advanced implementation is when, rather than considering certification as an end point, the company uses the ISO 9000 as a stimulus for rethinking how it could conduct its business more effectively. Finally, supportive implementation is when top management takes an active (and key) role in a number of crucial resource support areas such as fostering a quality culture, supervising employee behaviour, arranging training programs for employees in order to facilitate skill improvements, and ensuring that a continuous improvement cycle exists within the organization (Singh \& Mansour-Nahra, 2006; Nair \& Prajogo, 2009).

However, the way a supplier belongs to one category or another very much depends on the result of the audit carried out by their customer. In these audits it is possible to qualify the implementation levels of every aspect of ISO 9001 and help the customer to determine if the supplier is more focused on accomplishing quality assurance procedures, than on product or production processes. In other words, to determine if they are good suppliers or if there is room for improvement.

\section{Objectives}

The aim of this research is to analyse the levels of implementation of the international standard ISO 9001 in the wind power (WP) sector from the point of view of the customer, and provide guidelines for future improvement.

This study also seeks to address the lack of empirical evidence on the relationship between ISO 9001 implementation and SPAs that an extensive literature review revealed.

Our primary objective is to determine which of the ISO 9001 aspects have an impact on the level of ISO 9001 implementation. The way to achieve this is through a data analysis of the SPAs collected by a manufacturer in the WP sector. Using these audits, the manufacturer classifies its suppliers into three categories, and we assume these correspond to the implementation of ISO standards found in the literature.

Our secondary objective is to define the constructs, i.e. the ISO aspects which are correlated in the audits a firm makes of its suppliers, and to measure the impact these constructs have on the level of adoption as determined by the customer company. 


\section{Methodology}

In order to achieve our objectives, the research was carried out in WP sector supply chain firms (i.e. component suppliers, assemblers, and wind farm operation and maintenance services).

An extensive literature review reveals there is little empirical evidence of the relationship between ISO 9001 implementation and supplier activities (Lo \& Yeung, 2006; Prajogo et al., 2012). The majority of the contributions referenced in the literature review section are based on surveys (subjective data). In this paper we use primary data (objective data) from the SPAs of suppliers. One of this paper's authors is the Director of Global Quality for the wind turbine manufacturer concerned and has collected and compiled data from the audits of suppliers which, in turn, is one of the most valuable aspects of this paper's contribution.

The data used here are based on the audits of 90 technical suppliers to one of the largest wind turbine manufacturers and ranked in the top 15 largest companies in the sector in terms of installed power (MAKE Consulting, 2013; BTM Consult, 2014). Located in Europe, but with production centres in both North and South America, it employs more than 1,500 workers and has an income of over $€ 400 \mathrm{~m}$ per annum.

\subsection{Wind Turbine Manufacturer Supplier Audit}

The questionnaire used to assess the suppliers in the audit is based on the ISO 9001:2008 requirements and organized into 21 main "items" spread over the four main processes: (P1) Management system and responsibility, (P2) Resource management, (P3) Product completion, (P4) Measuring, analysis and improvement. These items, classified into the four main ISO processes, are presented in Table 1. 


\begin{tabular}{|c|c|}
\hline P1 & Management System and responsibility \\
\hline v1 & Quality Management System and responsibility (general requirements) \\
\hline v2 & Control of documentation \\
\hline v3 & Control of records \\
\hline $\mathrm{v} 4$ & Planning \\
\hline P2 & Resource management \\
\hline v5 & Competence, training and awareness \\
\hline v6 & Infrastructure and work environment \\
\hline P3 & Product completion \\
\hline $\mathrm{v} 7$ & Planning of product manufacture \\
\hline v8 & Customer related processes \\
\hline v9 & Design and development \\
\hline v10 & Purchasing process and information \\
\hline v11 & Supplier evaluation \\
\hline v12 & Product and service provision \\
\hline v13 & Product preservation \\
\hline v14 & Identification and traceability \\
\hline v15 & Verification of purchased product \\
\hline v16 & Control of monitoring and measuring equipment \\
\hline P4 & Measuring, analysis and improvement \\
\hline v17 & Monitoring and measurement of procesesses \\
\hline v18 & Monitoring and measurement of product \\
\hline v19 & Data analysis \\
\hline v20 & Control of nonconforming product \\
\hline v21 & Corrective and preventive actions \\
\hline
\end{tabular}

Table 1. Audited items on supplier site

\subsection{Sample and Audit Process}

Forty percent of the companies audited are global players and are referred to in the sector's specialized journals such as MAKE Consulting (2013) or BTM Consult (2014). Table 2 shows the scope of the companies audited.

\begin{tabular}{|c|c|c|c|c|c|}
\hline Location/ Employees & Europe & South America & North America & Asia & Total \\
\hline$>500$ & 8 & 5 & 1 & 8 & 22 \\
\hline $500-100$ & 15 & 3 & 3 & 3 & 24 \\
\hline$<100$ & 37 & 4 & - & 3 & 44 \\
\hline Total & 60 & 12 & 4 & 14 & 90 \\
\hline
\end{tabular}

Table 2. Audit scope 
The audits were carried out following the ISO 9001:2008 framework and under the supervision of one of the authors of this paper in his role as the Global Quality Director of the company. The audit team were trained in accordance with the company's audit procedures. All the suppliers audited work with the ISO 9001:2008 standard thanks to a specific requisite from the set of design requirements (IEC, 2010) that must be met to certify a wind turbine.

In addition, to become an authorized supplier, the audited companies had had to pass a previous assessment and selection process and product qualification, in accordance with the company's standard procedure. This procedure is a three-step process beginning with (i) supplier assessment, followed by (ii) supplier/component qualification and finishing when the (iii) supplier is authorized for future serial production. After approximately a year supplying components to the wind turbine manufacturer, the company's audit team visited the suppliers to carry out audits. These audits have three main objectives: (i) to monitor and verify the proper operation and implementation of the supplier quality management system, (ii) to demonstrate that customer requirements (purchase order, delivery time, technical specifications, drawings, customer quality requirements, and packaging) are effectively implemented and maintained over time, and (iii) to take any appropriate action to eliminate root causes of nonconformities and prevent their recurrence, and to identify any potential improvement areas.

At the end of the appraisal, a closed audit meeting is held with the suppliers. The scope of the meeting is to examine any major and/or minor findings and discuss any future opportunities for improvement. More importantly, the company auditors and the suppliers then develop a plan for improvement together.

The audits were performed in accordance with the procedures and standards of the wind turbine manufacturer and took between three and five days, depending on the size of the company and the complexity of the product being produced.

\subsection{Measures}

The company auditors graded each item on a 4-point scale. The items audited are closely connected to ISO 9001:2008, but as the audit was performed by the customer the answers focused on evaluating the supply performance related to the product. By using a scale where $0=$ not implemented item, $1=$ partially implemented item with nonconformities, $2=$ implemented item with observations and 3 = fully implemented item, each item's level of impact was then then able to be validated according to the value given in the answers, thus making it possible to determine the level of ISO implementation for each and every item asked about. As a result of the audit, the firm receives a Global Audit Score (GAS) when the average of all the audited items has been calculated. Following the criteria assigned to each 
company, we considered three levels of implementation. If the company scores $85 \%$ (GAS $>2.55$ ), the supplier has a HIGH level of implementation, if it is 70\% (2.55>GAS>2.1) the supplier has a MEDIUM level of implementation, otherwise the supplier is considered as having a LOW level of implementation $(\mathrm{GAS}<2.1)$.

\section{Results}

Below, we present the data collected from the supplier classification according to GAS (Table 3). What is made abundantly clear is that more than $40 \%$ of suppliers do not and cannot have a positive relationship with the firm because they are classified as LOW. Therefore, we cannot conclude that the ISO 9001 standard ensures a certain level of quality from a supplier i.e. a level which would mean that supplier could be considered an extended capability for the firm.

\begin{tabular}{|c|r|r|r|r|r|}
\hline Grade GAS & \multicolumn{1}{|c|}{ Europe } & South America & North America & Asia & Total \\
\hline High & 5 & 2 & 1 & 1 & 9 \\
\hline Medium & 31 & 7 & 1 & 4 & 43 \\
\hline Low & 23 & 4 & 2 & 9 & 38 \\
\hline Total & & & & & 90 \\
\hline
\end{tabular}

Table 3. Supplier classification according to Global Audit Score

The analysis is divided into three. First, we present a descriptive analysis of the 21 items, followed by a factor analysis which allows us to group the 21 items from the audits into latent factors. Finally, the U Mann-Whitney test is applied, enabling us to compare latent factors of the categorized suppliers by GAS.

In the Descriptive Analysis section, we analyse the implementation of the 21 items individually, while in Discussion and Findings, we argue the strengths and weaknesses of the sector and present potential areas for improvement. Table 4 shows that "Competence training and awareness" (v5-2.44), "Identification and traceability" (v14-2.4), "Product preservation" (v13-2.31) and "QMS and responsibility" (v1-2.29) are the items that obtained the best assessment in the implementation audits. In contrast, the items "Corrective and preventive actions" (v21-1.81), "Product and service provision" (v12- 1.88), "Data analysis" (v19-1.90) and "Planning of product manufacture" (v7-1.94) were those which obtained the poorest implementation ratings in the audits. 


\begin{tabular}{|c|c|c|c|c|}
\hline Item & ISO $9001: 2008$ Item description & $\mathbf{N}$ & Mean & $\begin{array}{c}\text { Standard } \\
\text { Desviation }\end{array}$ \\
\hline $\mathrm{v} 5$ & Competence, training and awareness & 75 & 2.44 & 0.54 \\
\hline v14 & Identification and traceability & 90 & 2.4 & 0.64 \\
\hline v13 & Product preservation & 85 & 2.31 & 0.69 \\
\hline v1 & Quality Management System and responsibility (General requirements) & 87 & 2.29 & 0.63 \\
\hline v15 & Verification of purchased product & 89 & 2.28 & 0.65 \\
\hline v17 & Monitoring and measurement of processes & 87 & 2.28 & 0.67 \\
\hline v3 & Control of records & 85 & 2.27 & 0.62 \\
\hline v10 & Purchasing process and information & 68 & 2.26 & 0.65 \\
\hline v16 & Control of monitoring and measuring equipment & 85 & 2.24 & 0.65 \\
\hline v18 & Monitoring and measurement of product & 87 & 2.24 & 0.76 \\
\hline v9 & Design and development & 11 & 2.15 & 0.73 \\
\hline v11 & Suppliers evaluation & 66 & 2.13 & 0.72 \\
\hline $\mathrm{v} 2$ & Control of documentation & 84 & 2.09 & 0.69 \\
\hline v8 & Customer related processes & 84 & 2.04 & 0.76 \\
\hline v20 & Control of nonconforming product & 88 & 2.02 & 0.63 \\
\hline $\mathrm{v} 4$ & Planning & 86 & 2.01 & 0.68 \\
\hline v6 & Infrastructure and work environment & 88 & 1.96 & 0.69 \\
\hline v7 & Planning of product realization & 86 & 1.94 & 0.71 \\
\hline v19 & Data analysis & 66 & 1.9 & 0.72 \\
\hline v12 & Product and service provision & 83 & 1.88 & 0.69 \\
\hline v21 & Corrective and preventive actions & 87 & 1.81 & 0.69 \\
\hline
\end{tabular}

Table 4. Descriptive analysis of 21 items

As a second step to our research methodology, we focussed on factor analysis of the data we collected in order to find homogeneous groups of correlated items that would help us verify the existence of latent variables indicating those ISO 9001 items that correlate with the levels of ISO 9001 implementation in the sector. The exploratory factor analysis, shown in Table 5, was performed using the Varimax rotation from the SPSS factor analysis procedure, to identify the latent dimensions (F1, F2, F3) derived from the data and used in the study. The scales were analysed in accordance with the recommendations of Ladhari (2010) who follows the criteria to retain items that (i) load at 0.50 or greater in a factor, (ii) do not load at greater than 0.50 in two factors and (iii) have an item reaching total correlation of more than 0.40 . 


\begin{tabular}{|c|c|c|c|}
\hline Items & F1 & $\mathbf{F} 2$ & F3 \\
\hline v16. Control of monitoring and measuring equipment & 0.812 & & \\
\hline v1. QMS and responsibility (general requirements) & 0.730 & & \\
\hline v6. Infrastructure and work environment & 0.692 & & \\
\hline v4. Planning & 0.689 & & \\
\hline v2. Control of documentation & & 0.780 & \\
\hline v12. Product and service provision & & 0.773 & \\
\hline v18. Monitoring and measurement of product & & 0.744 & \\
\hline v3. Control of Records & & 0.568 & \\
\hline v15. Verification of purchased product & & & 0.806 \\
\hline v8. Customer related processes & & & 0.683 \\
\hline v17. Monitoring and measurement of processes & & & 0.660 \\
\hline Cronbach's alpha & 0.695 & 0.749 & 0.600 \\
\hline$\%$ of variance explained & 21.75 & 20.78 & 17.54 \\
\hline
\end{tabular}

Table 5. Matrix rotated components using the Varimax extraction method

Prior to statistical analysis, several items were removed for two reasons: the inability to assess the requirement as a result of it not being applicable in the company (v9) or not being able to assess the item in the audit because of a lack of time (v5, v10, v11 and v19) during the visit. Finally, throughout the process of exploratory data analysis, v13, v20, v7, v14 and v21 were eliminated.

The correlation matrix was subjected to two tests: Bartlett's sphericity test [183.941; df 55; p value 0.000] and the Kaiser-Meyer-Olkin (KMO) index [0.768]. The Bartlett test's statistical confirmation of the existence of linear dependence between the variables (items) justified, in all cases, continuing the procedure. The KMO also confirmed that factor analysis was likely to generate satisfactory results (Visauta, 1998).

Confirmatory factor analysis (CFA) was applied to the sample data to verify the factor structure that emerged from the EFA. The reliability of the resulting factors was assessed using Cronbach's alpha. All the constructs had an alpha value of greater than 0.6 (Malhotra, 2004).

"Structural implementation" is the name we assign to the first factor (F1), as this factor focuses on the basic system requirements of assurance quality management. We called the second factor (F2) "Internal integration" and this consists of the requirements which drive the system such as document and record control and the performance of the product and its validation. Finally, the third factor (F3), coined "External integration and analysis", consists of requirements that most affect suppliers and customers, as well as process control. 
The final step was to measure the impact of the factors on the level of ISO implementation we considered for each supplier. Table 6, which compares the average of factors among the three groups (HIGH, MEDIUM, and LOW) determined by the GAS, shows the factors that most affect determining the level of implementation. F1 and F2, are significantly different between HIGH and MEDIUM ( $p$ value 0.026 and $p$ value 0.002 ) and MEDIUM and LOW ( $\mathrm{p}$ value 0.003 , $\mathrm{p}$ value, 0.030 ), but in F3 there are no differences between HIGH and MEDIUM ( $\mathrm{p}$ value 0.708), but rather they are between MEDIUM and LOW ( $\mathrm{p}$ value 0.002$)$.

In Table 6, we see that F1 and F2 differ in implementation levels from lowest level (near 0.5) to medium level (near 0) or highest level (near 1) in the same way as GAS differs. However, F3, never achieves a HIGH level (near 1), although it does achieve a medium level according to HIGH or MEDIUM GAS. F1 and F2 have to be considered as achieving a good fit in ISO 9001 implementations in this sector, but F3 does not differentiate between HIGH and MEDIUM instead it only differentiates between LOW and MEDIUM.

\begin{tabular}{|c|c|c|c|c|}
\hline & Companies & $\begin{array}{l}\text { F1. Structural } \\
\text { implementation }\end{array}$ & $\begin{array}{l}\text { F2. Internal } \\
\text { integration }\end{array}$ & $\begin{array}{l}\text { F3. External integration } \\
\text { and analysis }\end{array}$ \\
\hline $\mathrm{HIGH}$ & 10 & 0.972 & 1.025 & 0.242 \\
\hline MEDIUM & 28 & 0.245 & 0.082 & 0.414 \\
\hline LOW & 27 & -0.614 & -0.465 & -0.519 \\
\hline
\end{tabular}

Table 6. $F_{\mathrm{i}}$ average, depending on GAS (Global Audit Score) implementation level

\section{Discussion and Findings}

From the SPA data it is possible to confirm that ISO 9001 implementation levels differ, even when all of these suppliers have been ISO 9001 certified by a third party.

In Table 4, we see that the best implemented items are, "Competence training and awareness, "Identification and traceability", "Product preservation" and "QMS and responsibility". In this sense, our findings agree with Naveh and Marcus (2004) and Prajogo et al. (2012), who suggest that employee training and quality management practices, such as quality manual, polices, documentation and instructions, operation identification and traceability form part of the standard assimilation for a company (Naveh \& Marcus, 2004), as well as part of its daily routine and thus, are basic and essential requirements of ISO 9000 implementation (Prajogo et al., 2012). 
However, in Table 4 the most poorly implemented items are "Corrective and preventive actions", "Product and service provision", "Data analysis" and "Planning of product realization". All of these are related to product execution and continuous improvement. Thus, our findings forge a path (from the customer's point of view) for suppliers, i.e. suppliers must work to improve aspects related to "product and service provision", in the WP sector as these are the areas which have a direct impact on the final product; not to mention company performance. Therefore, and as a way to move beyond the standard alone, areas concerned with "continuous improvement" must be honed and perfected.

In our research, we found that different implementation "levels" can and do provide firms with opportunities for improvement, and we would go as far as to suggest these 'windows of opportunity' are created in accordance with how and to what extent a company has implemented the standard. According to the factor analysis, the sector has three groups of ISO requirements which follow a similar pattern to implementing the standard. Comparing averages of the factors found that the level of implementation depends on all the items studied and are grouped according to certain factors, although it has been shown that F3 (External integration and analysis) seldom, according to GAS, achieves the highest level of implantation in the sector.

Some studies in the literature highlight positive benefits when ISO is implemented, while others demonstrate that there is no discernable impact on a company's performance. From our point of view, as in other studies found in the literature, it is difficult to associate the relationships between ISO 9000 and its effect on business performance. A possible answer is that there are multiple-variables associated with business performance, such as financial factors, market environment, government policies and regulations etc., and therefore, the direct effect on business performance is very difficult to identify, even after carefully controlling samples. For this reason, we consider that a survey questionnaire is not an adequate tool with which to draw any conclusions about the impact ISO 9000 regulations may or may not have on a company's performance.

Instead, what we can conclude is that ISO 9000, depending on the "level" of implementation, does provide opportunities to identify and work on areas for improvement, thus becoming more competitive in the marketplace. Furthermore, certification bodies and the genuine commitment from top management play an important role in ensuring this competitive advantage. In other words, merely being accredited with ISO 9000 certification will not ensure that firms gain a competitive advantage over their rival competitors but, as Naveh and Marcus (2004) also state, if the standard is extremely well implemented internally and carefully coordinated externally with suppliers and customers and becomes part of their daily practices, then it can be used as a springboard for the change which, in turn, would result in the much sought after 'competitive advantage'. 


\section{Conclusion}

As a result of this study, several conclusions can be drawn. First, there are some weaknesses in the sector which need to be addressed as they are "Product and service provision", "Data analysis", and "Corrective and preventive actions", all of which are related to the performance of the product and its processes, as well as its continuous improvement. In other words, analysing these would determine any corrective and/or preventative action to be taken. These findings show that SPAs play a unique and specific role by helping to identify system weaknesses that affect product and processes, by identifying opportunities for change and by suggesting areas for improvement.

Secondly, we can also demonstrate that there are companies in the WP industry, that have been certified ISO 9001:2008 by third parties, who employ varying levels of implementation. This indicates that levels of ISO 9001 implementation and development are related to management commitment and culture and the good practices of the organization in question. In fact, top management plays a crucial role in a company moving beyond the standard.

Finally, from the results of this work, a "road map" towards improvement can be drawn. This road map would enable companies in the sector to go beyond simply applying standard and allow them to fully exploit ISO 9001 certification by using it as a lever for change. In other words, the statistical analysis shows us that companies rated as LOW must improve aspects of F1 (Structural implementation) and F2 (Internal integration) to become MEDIUM and then continue those improvements until they reach the so-called HIGH category. However, in the case of F3 (External integration and analysis) only one step from the LOW to MEDIUM or even HIGH category is required. For the companies in the MEDIUM category, they must consolidate and improve factors F1 and F2, but they do not need to focus on F3 to become HIGH. Firms with the highest implementation levels use ISO 9001 certification as a "lever" to attain business excellence and their daily practices often go beyond the requirements of ISO 9001 certification to follow the criteria we found in the literature. This article provides some theoretical implications i.e. viewing the standard from the customer's perspective which, in turn, leads to an understanding of the standard from the point of view of the customer's needs. Thus, the usefulness of the audits is clearly demonstrated along with the overall objective of ISO 9001: customer satisfaction.

This article has some limitations as it focuses only on the WP sector, although its findings could be extrapolated to similar sectors of high technology and high customization. It also highlights several implications for managers i.e. certification only implies conformity to the standard and SPAs provide valuable information about supplier quality commitment. Going beyond certification involves the support and commitment of management in a company's daily practices. 


\section{Acknowledgement}

The authors are grateful for the financial support from the Spanish Ministry of Economy and Competitiveness ECO2013-46954-C3-3-R.

\section{References}

Anderson, S.W., Daly, J.D. \& Johnson, M.F. (1999). Why firms seek ISO 9000 certification: regulatory compliance competitive advantage?. Production Operations Management, 8(1), 28-43. https:/doi.org/10.1111/j.1937-5956.1999.tb00059.x

Bradley, M. (1994). Starting total quality management from ISO 9000. The TQM Magazine, 6, 50-55. https://doi.org/10.1108/09544789410052778

Brown, A., Wiele, T. van der, \& Loughton, K. (1998). Smaller enterprises' experiences with ISO 9000. International Journal of Quality and Reliability Management, 15(3), 273-285.

https:/doi.org/10.1108/02656719810198935

BTM Consult (2014). International Wind Energy Development. Supply Chain Assessment. London: BTM Consultant.

Casadesús, M., \& Karapetrovic, S. (2005). Has ISO 9000 lost some of its lustre? A longitudinal impact study. International Journal of Operations and Production Management, 6, 580-596. https:/doi.org/10.1108/01443570510599737

Castka, P., Prajogo, D., Sohal, A., \& Yeung, A.C.L. (2015). Understanding firms' selection of their ISO9000 third-party certifiers. International Journal Production Economics, 162, 125-133. https:/doi.org/10.1016/j.ijpe.2015.01.012

Chow-Chua, C., Goh, M., \& Boon-Wan, T. (2003). Does ISO 9000 certification improve business performance? International Journal of Quality and Reliability Management, 20(8), 936-953. https:/doi.org/10.1108/02656710310493643

Curkovic, S., \& Pagell, M. (1999). A critical examination of the ability of ISO 9000 certification to lead a competitive advantage. Journal of Quality Management, 4(1), 55-67. https:/doi.org/10.1016/S10848568(99)80095-9

Davis, B. (2004). One standard fits all. Professional Engineering, 17 (9), 43-45.

Dimara, E., Skuras, D., Tsekouras, K., \& Goutsos, S. (2004). Strategic orientation and financial performance of firms implementing ISO 9000. The International Journal of Quality and Reliability Management, 21(1), 72-90. https:/doi.org/10.1108/02656710410511704 
Ferenčíková, D., \& Briš, P. (2013). Customer Audits as a Quality Control Tool for Both Suppliers and Customers. International Journal of Social, Behavioral, Educational, Economic, Business and Industrial Engineering, 7(8), 2336-2339.

IEC 61400-22. International Electrotechnical Commission (2010). Wind Turbines - Part 22: Conformity testing and certification.

Karapetrovic, S., \& Willborn, W (2000). Quality assurance and effectiveness of audit systems. International Journal of Quality and Reliability Management, 17(6), 679-703. https:/doi.org/10.1108/02656710010315256

Kluse, C. (2013). Third-party Quality Management System audits: perceptions, limitations, and recommended improvements. Quality Issues and Insights in the 21 Century, 2(1), 28-45.

Ladhari, R. (2010). Developing e-service quality scales: a literature review. Journal of Retail and Consumer Services, 17, 464-477. https:/doi.org/10.1016/j.jretconser.2010.06.003

Lo, V.H.Y., \& Yeung, A. (2006). Managing quality effectively in supply chain: a preliminary study. Supply Chain Management: An International Journal, 11(3), 208-215. https:/doi.org/10.1108/13598540610662103

MAKE Consulting (2013). Market Report Global Wind Power Supply Chain. Aarhus: MAKE.

Malhorta, N.K. (2004). Marketing research and applied orientation, 4th ed. Englewood Cliffs: Prentice Hall Inc.

Martínez-Costa, M., Martínez-Lorente, A. R., \& Choi, T. Y. (2008). Simultaneous consideration of TQM and ISO 9000 on performance and motivation: An empirical study of Spanish companies. International Journal of Production Economics, 113(1), 23-39. https:/doi.org/10.1016/j.ijpe.2007.02.046

Morris, P.W. (2006). ISO 9000 and financial performance in the electronics industry. Journal of American Academy of Business, 8(2), 227-235.

Nair, A., \& Prajogo, D. (2009). Internalisation of ISO 9000 standards: The antecedent role of functionalist and institutionalist drivers and performance implications. International Journal of Production Research, 47(16), 4545-4568. https:/doi.org/10.1080/00207540701871069

Naveh, E., \& Marcus, A.A. (2004). When does the ISO 9000 quality assurance standard lead to performance improvement? Assimilation and going beyond. IEEE Transactions on Engineering Management, 51(3), 352-363. https:/doi.org/10.1109/TEM.2004.830864

Naveh, E., \& Marcus, A. (2005). Achieving competitive advantage through implementing a replicable management standard: Installing and using ISO 9000. Journal of Operations Management, 24(1), 1-26. https:/doi.org/10.1016/j.jom.2005.01.004 
Power, D., \& Terziovski, M. (2007). Quality audit roles and skills: Perceptions of non-financial auditors and their clients. Journal of Operations Management, 25, 126-147. https:/doi.org/10.1016/j.jom.2006.02.005

Prajogo, D., Huo, B., \& Han, Z. (2012). The effects of different aspects of ISO 9000 implementation on key supply chain management practices and operational performance. Supply Chain Management: An International Journal, 17(3), 306-322. https:/doi.org/10.1108/13598541211227135

Prasad, H.C.S., Kamath, G., Barkur, G., \& Nayak, R. (2016). Does Supplier Evaluation Impact Process Improvement? Journal of Industrial Engineering and Management, 9(3), 708-731.

https:/doi.org/10.3926/jiem.1777

Romano P. (2002). Impact of supply chain sensitivity to quality certification on quality management practices and performance. Total Quality Management, 13(7), 981-1000.

https:/doi.org/10.1080/0954412022000017067

Singh, P.J \& Mansour-Nahra, P. (2006). ISO 9000 in the public sector: A successful case from Australia. The TQM Magazine, 18(2), 131-142. http://dx.doi.org/10.1108/09544780610647856

Sroufe, R., \& Curkovic, S. (2008). An examination of ISO 9000:2000 and supply chain quality assurance. Journal of Operations Management, 26(4), 503-520. https:/doi.org/10.1016/j.jom.2007.06.006

Tsekouras, K., Dimara, E., \& Skuras, D. (2002). Adoption of a quality assurance scheme and its effects on firm performance: a study of Greek firms implementing ISO 9000. Total Quality Management, 13(6), 827-841. https:/doi.org/10.1080/0954412022000010163

Visauta, B. (1998). Análisis estadístico con SPSS para Windows. Volumen II estadística multivariante. Madrid: McGraw Hill.

Zaramdini, W. (2007). An empirical study of the motives and benefits of ISO 9000 certification: the UAE experience. International Journal of Quality and Reliability Management, 24(5), 472-491. https:/doi.org/10.1108/02656710710748358

Journal of Industrial Engineering and Management, 2016 (www.jiem.org)

Article's contents are provided on an Attribution-Non Commercial 3.0 Creative commons license. Readers are allowed to copy, distribute and communicate article's contents, provided the author's and Journal of Industrial Engineering and Management's names are included. It must not be used for commercial purposes. To see the complete license contents, please visit http://creativecommons.org/licenses/by-nc/3.0/. 